\title{
Influence of Calcined Clay on the Strength Characteristics and Microstructure of Recycled Aggregate Concrete for Sustainable Construction
}

\author{
Oluwarotimi M. Olofinnade ${ }^{1, a^{*}}$ and Isaac T. Oyawoye $e^{1, b}$ \\ ${ }^{1}$ Department of Civil Engineering, Covenant University, Ota, Ogun state, Nigeria \\ *arotimi.olofinnade@covenantuniversity.edu.ng, bisaac.oyawoye@stu.cu.edu.ng
}

Keywords: Calcined clay, Compressive strength, Natural aggregate, Recycled concrete aggregate, water absorption, workability, porosity, Sustainability.

\begin{abstract}
Utilization of concrete wastes as aggregate in conventional concrete is regarded as a promising way of achieving sustainability within the built-up environment. This study investigated the performance of high strength concrete produced using recycled aggregate (RCA) with the addition of calcined clay in the concrete mixes. The recycled aggregate was sourced from concrete rubbles and treated by soaking in water, while calcined clay was sourced from the pilot pozzolana plant of the Nigerian Building and Road Research Institute (NBRRI). The recycled concrete aggregates were used as a replacement for coarse aggregate at levels of 0,20,40, 60, 80 and 100\%, using a mix ratio of 1:1:2 at a constant water-binder ratio of 0.25 . Superplasticizer was added to ensure the workability of the mixes. The calcined clay was added at 15 and $20 \%$ partial replacement for cement in the mixes. Physical and chemical properties of the materials used were determined, while the workability of the concrete mixes was examined using the slump. The compressive strength of the hardened concrete was determined after 7, 28 and 56 days of curing using $100 \mathrm{~mm}$ cube samples. Scanning Electron Microscope (SEM) was used to evaluate the morphology of selected concrete. Results showed that soaking of the recycled aggregate in water limit the water absorption rate of the RCA aggregates in the mixes, while the addition of calcined clay was observed to slightly reduce the workability of the concrete mixes. A reduction trend in compressive strength was noticed as the percentage of recycled aggregate increases, however, a significant increase in compressive strength was observed with the addition of calcined clay at $15 \%$ cement replacement. An optimum concrete mix containing $20 \%$ recycled aggregate and $15 \%$ calcined clay showed improve performance compare to the other mixes. The implication of these results suggests that recycled concrete aggregate can be used for the production of sustainable structural concrete.
\end{abstract}

\section{Introduction}

The drive for sustainability by the construction industry stems from the constant and incessant depletion of the earth's natural resources as well as the adverse impact of these activities on the environment resulting in the emission of greenhouse gases [1]. Concrete is one of the most widely used material for construction and as such a lot of natural resources used for its production are constantly depleted for its production [2]. According to the study of US concrete report [3] and Neville [4], it was mentioned that concrete is basically a man-made material that comprises of cement, aggregates and water with widespread applications for constructing civil engineering structures. The cementing and water constituents of concrete are its most important components that bind the aggregate materials together [4], while the coarse aggregates account for $70-80 \%$ of the total volume of concrete and this heavily burdens the quarry reserves; hence the need for adopting alternative material to preserve the raw reserves. Meanwhile, Mo et al. [5] reported that with the increasing growth of the construction industry in most nations of the world today, it is expected that there will be an increase in the excessive mining of the natural resources such as the raw materials for cement production and new aggregates which may lead to pollution, ecological imbalance and damages to the environment. For instance, Soutous et al. [6] stated that an approximate amount of about 275 million tons of raw aggregates are extracted annually in the United Kingdom (UK) alone and while 